\title{
Correction: The use of microbial inoculants for biological control, plant growth promotion, and sustainable agriculture: A review
}

\author{
Ahmed S. M. Elnahal • Mohamed T. El-Saadony • Ahmed M. Saad • El-Sayed M. Desoky • \\ Amira M. El-Tahan • Mostafa M. Rady • Synan F. AbuQamar 1 - Khaled A. \\ El-Tarabily
}

Published online: 7 February 2022

(C) Koninklijke Nederlandse Planteziektenkundige Vereniging 2022

\section{European Journal of Plant Pathology}

https://doi.org/10.1007/s10658-021-02393-7

This erratum is published as typesetter overlooked several author corrections during proofing.

Original article has been updated.

The online version of the original article can be found at https://doi.org/10.1007/s10658-021-02393-7

\section{A. S. M. Elnahal \\ Department of Plant Pathology, Faculty of Agriculture, Zagazig University, Zagazig 44511, Egypt}

\section{T. El-Saadony}

Department of Agricultural Microbiology, Faculty of Agriculture, Zagazig University, Zagazig 44511, Egypt

\section{A. M. Saad}

Department of Biochemistry, Faculty of Agriculture, Zagazig University, Zagazig 44511, Egypt

E.-S. M. Desoky

Department of Botany, Faculty of Agriculture, Zagazig

University, Zagazig 44511, Egypt

\author{
A. M. El-Tahan \\ Department of Plant Production, Arid Lands Cultivation Research \\ Institute, The City of Scientific Research and Technological \\ Applications, SRTA-City, Borg El Arab, Alexandria, Egypt \\ M. M. Rady \\ Department of Botany, Faculty of Agriculture, Fayoum \\ University, Fayoum 63514, Egypt

\footnotetext{
S. F. AbuQamar $(\bowtie)$

Department of Biology, College of Science, United Arab Emirates University, Al-Ain 15551, United Arab Emirates e-mail: sabuqamar@uaeu.ac.ae

K. A. El-Tarabily $(\bowtie)$

Department of Biology, College of Science, United Arab Emirates University, Al-Ain 15551, United Arab Emirates e-mail: ktarabily@uaeu.ac.ae
} 